\title{
Building for Biology: A Gene Therapy Trial Infrastructure
}

\author{
SAMUEL TAYLOR-ALEXANDER \\ MONASH UNIVERSITY \\ COURTNEY ADDISON ${ }^{2}$ \\ MONASH UNIVERSITY
}

\section{Keywords}

infrastructure; clinical trials; gene therapy; cystic fibrosis; regulation; rare diseases

\begin{abstract}
In this article, we examine the construction of the infrastructure for a Phase II gene therapy trial for Cystic Fibrosis (CF). Tracing the development of the material technologies and physical spaces used in the trial, we show how the trial infrastructure took form at the uncertain intersection of scientific norms, built environments, regulatory negotiations, patienthood, and the biologies of both disease and therapy. We define infrastructures as material and immaterial (including symbols and affect) composites that serve a selective distributive purpose and facilitate projects of making and doing. There is a politics to this distributive action, which is itself twofold, because whilst infrastructures enable and delimit the movement of matter, they also mediate the very activity for which they provide the grounds. An infrastructural focus allows us to show how purposeful connections are made in a context of epistemic and regulatory uncertainty. The gene therapy researchers were working in a context of multiple uncertainties, regarding not only how to do gene therapy, but also how to anticipate and enact ambiguous regulatory requirements in a context of limited resources (technical, spatial, and financial). At the same time, the trial infrastructure had to accommodate Cystic Fibrosis biology by bridging the gap between pathology and therapy. The consortium's approach to treating CF required that they address concerns about contamination and safety while finding a way of getting a modified gene product into the lungs of the trial participants.
\end{abstract}

\section{Introduction}

Standing in front of an audience in a London auditorium in May 2015, Dr. Eric Alton began a talk much awaited by the United Kingdom's Cystic Fibrosis (CF) community. He was there to present

Samuel Taylor-Alexander, Email: Sam.Taylor-Alexander@monash.edu 2Courtney Addison, Email: Courtney.Addison@monash.edu

Copyright (C) 2017 (Samuel Taylor-Alexander and Courtney Addison). Licensed under the Creative Commons Attribution Non-commercial No Derivatives (by-nc-nd). Available at estsjournal.org. 
the results of a Phase II clinical trial in which 140 CF patients received an experimental gene therapy. The presentation was live streamed to some forty-people gathered in a lecture theatre at Edinburgh's Western General Hospital. During his talk, Alton alternated between describing the scientific details of the trial (its aims, methods, results), and its story: the setbacks the research Consortium dealt with, and the workarounds they came up with in response. Before the Consortium's 2001 beginnings the gene therapy field had almost collapsed, though it has since been revived. The United Kingdom Cystic Fibrosis Consortium (hereafter the UKCFC, or "the Consortium") had weathered these changes, and pressed through many challenges within their own research. As Alton narrates it, the Consortium have always been vulnerable to the complexities of Cystic Fibrosis and the uncertainties of gene therapy. When the trial started, they did not know how much gene therapy a patient could inhale, so they looked to smoke inhalation studies and gave it their best guess. They had no way of knowing how risky their treatment might be to the general population, so they erred on the side of caution and repurposed breathing booths to dose patients. Alton portrayed his research colleagues as humble and uncertain, always ready to improvise, and endlessly tenacious.

The story he told was one of pioneering research that required his group to produce what we see as a novel infrastructure composed of material and conceptual elements. To make sense of this we draw on recent social science scholarship that examines infrastructures as "things and also the relation between things" (Larkin 2013: 329). Doing so reveals both how the right infrastructural arrangements are productive of scientific practice and that they make the uncertainties associated with new medical projects manageable. Cutting edge scientific research is fundamental to the United Kingdom's national identity and financial growth (Gibbons et al. 1994). In a context of increased international competition for $R \& D$ investment, the UK government has implemented new funding and regulatory measures with the purpose of protecting and furthering the local bioeconomy (Gardner and Webster 2016).

The Consortium's position was one in which they had both to answer to regulators and to produce many of the standards against which they would be judged, partly due to a lack of gene therapy-specific regulation. At the same time, they were negotiating a new and complex science that repeatedly presented them with unforeseeable difficulties. This tension was formative of the trial's ad hoc progression. Here, examining infrastructures becomes an entry point for understanding knowledge making in a context of regulatory and scientific uncertainty.

Tracing the development of the material technologies and physical spaces used in the trial, we show how a trial infrastructure was produced at the intersection of scientific and regulatory norms (e.g. good science, patient safety, scientific accountability), social commitments (e.g. to patient-publics), and the practical difficulties of doing gene therapy. The gene therapy consortium was working in a context of multiple uncertainties regarding how to do gene therapy, and how to anticipate and enact ambiguous regulatory requirements in a context of limited resources (technical, spatial, and financial). At the same time, the trial infrastructure had to accommodate Cystic Fibrosis biology by bridging the gap between pathology and therapy. The consortium's approach to treating CF required that they address concerns about contamination and safety while finding a way of getting a modified gene product into the lungs of the trial 
participants. The group were thus navigating complex biological, social, and regulatory factors, and we argue that one way they managed to do so was by constructing an infrastructure that would effectively facilitate their practice and distribute the materials on which it relied.

\section{Infrastructures}

STS and neighboring disciplines have traditionally conceived of infrastructures as built networks that facilitate the circulation of resources. Infrastructures were held to be invisible and enduring, conduits that worked in the background often over vast expanses of space (c.f. Star 1999). Classic examples include railroad networks and electrical grids, though more recent scholarship has expanded in such a way as to think of infrastructures in relation to urban social life (Simone 2004), planetary science (Vertesi 2014), and indigenous cultural production (Christen 2006). As befits this grand-scale reading, infrastructures are often engaged with in their capacity as agents of state or developmentalist power; this reading in turn invites analyses of how resources are distributed or blocked from reaching certain people or places (c.f. Howe et al. 2016; Simone 2004; Street 2014, 2016). Perhaps surprisingly, theorizations of infrastructure in relation to medicine are few ${ }^{3}$ although writing on clinical trials in resource-poor settings has engaged with infrastructural lack and how this intersects, for example, with global regulatory systems (see Geissler 2013; Petryna 2005).

More recently, attention has turned to the immaterial effects of infrastructure. It is not only vehicles, water, power, and the likes whose movement is facilitated by infrastructures; moral sensibilities, political ideology, and social meanings are similarly disseminated (Larkin 2013). Thus, a rural Peruvian road project is simultaneously a "promise of emancipatory modernity," suggesting a bright economic future enabled by connectivity and political integration (Harvey and Knox 2012: 523). Moreover, infrastructures themselves are not wholly material, as proliferating digital networks make clear. Rather, as anthropologist Brian Larkin's reading of Collier (2011) shows, physical components articulate with political rationalities and administrative techniques to produce functional infrastructures. Understood as a material-social composite, it becomes possible to consider infrastructural effects beyond the circulation of resources. Casper Bruun Jenson and Atsuro Morita (2015) interrogate how infrastructures bring about new nature/culture assemblages that unite ecological actants like rice and horticultural technologies. They argue that infrastructures "hold the capacity for doing such diverse things as making new forms of sociality, remaking landscapes, defining novel forms of politics, reorienting agency, and reconfiguring subjects and objects all at once" (83 emphasis in original).

Somewhere along this thought trajectory, the notion of infrastructure lapses into generality and loses its analytic purchase. Once conceptualized "as emergent systems that produce variable practical ontologies" (Jensen and Morita 2015: 84, emphasis in original), it becomes possible to apply the label to almost any phenomena imaginable. Perhaps more importantly, these themes

${ }^{3}$ While historical scholarship shows that the birth of biomedicine involved novel architectural developments (Foucault 2012; Timmermans and Berg 2010; Keating and Cambrosio 2003), this literature stops short of theorizing biomedical "infrastructure." 
of nascence and contingency are already accommodated by the concept of the assemblage, which, Marcus and Saka (2006: 106) note, "functions best as an evocation of emergence and heterogeneity... without rigidifying into the thingness of final or stable states." This analytic need thus met, what does infrastructure offer? Whittling the term to its bare bones, Larkin (2013) calls infrastructures "matter that enable[s] the movement of other matter," "things and also the relation between things," and "objects that create the grounds on which other objects operate" (329). We might extract from Larkin's reading two essential features of an infrastructure: first, that it permits the movement of some other substance; and second, that the infrastructure itself is supportive of another level of activity or production. To summarize, infrastructures are material and immaterial (including symbols and affect) composites that serve a selective distributive purpose and facilitate projects of making and doing. The infrastructures of interest to us, by this definition, are those that provide the grounds for the administration of the CF gene therapy.

Thinking with Larkin's terms reveals a key dimension of sociotechnical arrangements that otherwise escape analytic attention. Infrastructures enable the movement of matter and constitute the grounds of activity. We use the concept of infrastructure to highlight the conditions necessary for researchers to produce their gene therapy, administer it to patients, and assess the trial's outcomes. Thinking in terms of infrastructure points to how the production of a specific, local body of knowledge (here data on the safety and efficacy of a clinical gene therapy) relies upon a careful distribution of information and resources, achieved in our case by the consortium's repurposing and innovation of various facilities, instruments, and ideas. There is a politics to this distributive action, which is itself twofold, because whilst infrastructures enable and delimit the movement of matter, they also mediate the very activity that they provide the grounds for. We stay close to the notion that infrastructures are that which directly supports (and limits) movement and activity, focusing on the novel sociotechnical arrangements that the consortium produced, while acknowledging that these are undergirded by other arguably infrastructural elements that we do not discuss. As we go on to show, the production of robust infrastructures is fundamental for scientific practice in conditions of uncertainty."

\section{Methods}

This article is based on two research projects. One (STA) investigates rare disease regulation in the UK. The other (CA) is a study of the social shaping of human gene therapy, also with a UK focus. As part of these projects the authors (independently) conducted six interviews with different members of the UK Cystic Fibrosis Consortium. Interviewees came from each of the Consortium's three sites (Oxford, London, Edinburgh) and included clinicians, basic scientists, and trial coordinators. It is worth noting that the group is highly translational and members who identify as, for example, clinicians, will often be involved in bench science, and vice versa. In each case interviews were semi-structured and ran for approximately an hour. Though the authors

" This observation is akin to Jasanoff's $(2013,113)$ articulation of standards as "co-produced responses to technoscientific and political uncertainty." 
used different interview guides, both covered the establishment of the Consortium, details of their trials, and regulation. Together these interviews yield a comprehensive and polyvocal narrative of the Consortium's efforts to bring about a therapy for Cystic Fibrosis. One interview was accompanied by a laboratory visit (STA), and both authors attended the Consortium's public results presentation, CA from the live London event and STA from the streamed Edinburgh session. The authors analyzed the publicly available trial protocol together. Interview transcripts, field notes, and trial documents (the protocol and resulting publications) were coded thematically with the aim of determining how the Consortium made a space for their research in both the gene therapy field and the UK regulatory context. This process drew our attention to how the trial's material constitution came to enact both compliance with regulatory standards and proactive innovation by the research team, while simultaneously positioning CF patients as research subjects, gene therapy as a viable scientific pursuit, and the Consortium as agents of a new medical enterprise.

\section{Cystic Fibrosis and the Gene Therapy Consortium}

Cystic Fibrosis (CF) is a rare genetic disorder caused by up to 2000 mutations in the Cystic Fibrosis Transmembrane Conductance Regulator (CFTR) gene. The CFTR gene is important for regulating fluid within cells, with the result that patients suffering from CF often have very salty sweat, thick mucus in their lungs and airways, and often more systemic issues. Approximately five in 10,000 people globally develop CF, making this a rare disease by official measures. However, it is concentrated in European populations, for whom it is "the most common lifethreatening recessive genetic disease" (Corvol et al. 2016: 40). Patients have experimented with treatments ranging from dietary management and exercise therapy to antibiotics and steroids. More recently, small molecule medicines have been trialed with some success in a subset of patients, and gene therapy has been explored. The UK Cystic Fibrosis Gene Therapy Consortium pursue the latter approach.

For single gene diseases like $\mathrm{CF}$, gene therapy is a compelling therapeutic candidate. In theory, administering whole healthy genes to patients is a way of resolving disease from the roots up. It seems especially suited to conditions like $\mathrm{CF}$, where the problematic gene might be afflicted by any of 2000 mutations: gene therapy should resolve the disease irrespective of mutation type. Thus, when gene therapy clinical trials began in the 1990s, Cystic Fibrosis was a popular candidate. Since then, however, attempts to medicate CF patients in this way have come up against a litany of roadblocks--biological, political, and practical. Because gene therapy differs significantly from previous kinds of medicine its implementation was governed by a patchwork of pre-existing and newly drafted regulations. Researchers were negotiating unfamiliar bureaucratic conditions and complex technical scientific issues at the same time, often with little guidance on how to do either. At the end of the 1990s when a patient died in an American gene therapy clinical trial (not for $\mathrm{CF}$ ), the field was severely shaken and many trials stopped. In the United Kingdom at the time several groups were working on gene therapies for $\mathrm{CF}$, but the researchers who went on to form the consortium were the only ones who persisted through the 
field's lull. Today they are one of only a few groups still working on a CF gene therapy, with others in Adelaide, Australia and Iowa, US.

The Consortium came about from the impetus of the UK's CF patient community, who are a particularly proactive example of patient-driven research. The Cystic Fibrosis Trust, a national charity then led by for parliamentarian Rosie Barnes, OBE, launched an initiative to unite three previously independent academic research groups in 2001. These groups, in Oxford, London, and Edinburgh, had a breadth of expertise and experience that Barnes and the CF Trust believed would be more effective if combined. The result was the UKCFC. In coming together, the groups modified their organization, focus, and facilities, perhaps most significantly by moving away from what they describe as an academic research program, to focus more directly on producing a therapy. As one of the consortium members explained, "the philosophy is actually to work as a pharmaceutical company rather than as an academic group, because a pharmaceutical company always gets its products through its pipeline...an academic group will always have another interesting question to ask." Reorganizing in this way meant the researchers were working more closely to the Trust's interests. For their part, the CF Trust provided both significant financial support to the group and, perhaps even more crucially, mediated access to a patient body that was unusually large by gene therapy standards (helped, paradoxically, by the prevalence of this rare disease).

\section{"Tooling up": Preliminary Preparations for a Clinical Trial}

Before they could proceed with a clinical trial proper, the consortium had various small issues to straighten out. The three groups had been working independently, and had to bring together their expertise across their three geographically distant sites and agree on a program of research that would utilize all of their respective expertise. In this section, we trace their early efforts to lay the groundwork for the Phase II clinical trial that was to come. These efforts included constructing a gene delivery system that had minimal side effects and was capable of getting the treatment into patients' bodies, while accounting for the social context of highly networked patients who, it was feared, might discuss their responses with one another and thereby unblind the trial. The preparations being made were all in one way or another directed at moving a therapeutic agent from university laboratories into patients' bodies. In what follows we describe some of the formative work that took place to put in motion this circulation of bodies and things and support the group's research activities more broadly. Interpreting this work through the lens of infrastructures allows us to highlight the distributive activity at the heart of the CF clinical trial and the ways in which the research team made space for the uncertainties they encountered as their project progressed.

${ }^{5}$ Most gene therapy trials in the UK address rare diseases, often affecting a very limited number of patients. It is not uncommon for a gene therapy clinical trial to have only a handful of patients (often numbering in the single digits), making this field of research a far cry from traditional large scale randomized clinical trials. 


\section{Side Effects}

In 2009 the consortium initiated a pilot study at the London site. The pilot was based on earlier Phase I research led by Eric Alton, which had shown, "a significant correction in chloride abnormality in the patients receiving active treatment" (Alton et al. 1999: 947). (The CFTR protein that is impaired in CF patients controls chloride transport throughout the body and produces these patients' characteristic symptoms of viscous mucus build-up and salty sweat.) With chloride abnormality taken as a key indicator of efficacy, this finding effectively served as proof of concept. Following this early work, the Consortium first went about trying to minimize side effects of the gene therapy, developing clinical assays to gauge its effectiveness, and exploring different methods for producing and delivering it in a clinical setting. The team chose to design the therapy so that it could be inhaled with a nebulizer, an option that seemed to fit well with the often-concentrated effects of CF in the lungs and airways.

Patients who had received earlier versions of the gene therapy in prior studies had reported mild, flu-like symptoms following its administration. This posed a problem for running a double-blind placebo-controlled trial (as the Phase II trial was envisioned) in a relatively small, tight knit patient community. The researchers were concerned that participants would deduce if they were in the control group (or not) based on how they felt after dosing and thus risk unblinding the cohort. One of the first steps the consortium took in response to this issue involved reworking the gene therapy itself. The team at Oxford designed a plasmid that "was devoid of the structures that give the inflammatory response" (Researcher 3) and featured a promoter that would see the gene activated more slowly, with a longer effect. With the plasmid thus developed, the consortium began the pilot study: a first in man, single dose safety test.

This pilot was conducted in London with 35 participants who were divided into three dosage groups. Just under half of the participants $(n=17)$ received a $20 \mathrm{ml}$ dose, with the rest of the participants receiving $10 \mathrm{ml}(\mathrm{n}=10)$ and $5 \mathrm{ml}(\mathrm{n}=8)$. The redesigned plasmid failed to avoid the flu-like side effects, especially amongst those participants who were receiving the highest $(20 \mathrm{ml})$ dosage. "We tried a number of things to get round that," one researcher explained, "...slowing the nebulizer down, saying if you just take it for a minute and then have a break, and then take it for a minute longer and we did it over a period of a couple of hours." The team modified their protocol to accommodate those attempts, delaying the trial's progress. Slowing down the nebulizer did not work, nor did administering anti-inflammatory drugs or corticosteroids alongside the gene therapy. Decreasing the dose, however, helped. Amongst these lower-dosed individuals, "Some patients still had a little twicker of temperature or something so we built into the protocol that we would give paracetamol around the time of the dosing" (Researcher 3).

These efforts speak to how the trial had to achieve a number of desired effects, which were attained through what we consider to be a scientific infrastructure. The CF trial cohort needed to be brought together with other essential components of the trial in a way that enabled the Consortium to run a double-blinded clinical trial. These components included the modified gene product, the delivery apparatus (nebulizer), and a vector--an entity that could carry the gene product into patients' bodies and cells. The initial steps the Consortium took were also responsive to the difficulties associated with developing a vector for use in a tight-knit 
community, where patients' hopes and acuity might jeopardize the scientific standards of the trial. Though the CF community was an essential part of the trial infrastructure (providing patient access and much of the funding), they also represented an obstacle to conducting a rigorous (blinded) trial. Here, something as mundane as paracetamol was given profound political importance. It mediated the possible epistemic consequences of bringing together two animated infrastructural components, allowing for the production of knowledge in accordance with the norms of science. Using infrastructure as a concept with which to think through these preparatory activities draws our attention to the material requirements of the trial (the bodies, vector, etc.) and to the particular order in which they had to be arranged to properly realize the consortium's scientific aims. The trial infrastructure, even at this early stage, is thus at the same time both produced by the research group, and itself productive for reaching their goals.

\section{Finding and Mixing a Vector}

In addition to ensuring the trial stayed blinded, the researchers had to get the therapy into the lungs, which involved selecting a "vector" to package the genes in. Most gene therapists use viruses to deliver their genes--in fact non-viral vectors are relatively uncommon. The Consortium, however, used lipids-small fat globules-to envelope and carry the therapeutic DNA into participants' airways. This involved mixing the DNA and lipid together shortly before treatment, a process that proved harder than anticipated when the scientists increased the volume of the substances (as was necessary for moving the work out of the laboratory and into the greater number of patients the clinical trial would accommodate). A researcher described it this way:

So the way it is told is not quite the way it actually happened but the way it is told is that the regulators asked us how we were going to mix these two vials [of lipid and DNA] together. Actually we had already noticed that, the vials each have $5 \mathrm{mls}$ of stuff in them... so you want to mix two lots of $5 \mathrm{mls}$ together to make $10 \mathrm{mls}$ and... of course we weren't doing that experiment, we were actually mixing 100 microliters, 0.1 of a $\mathrm{ml}$ of the two things together and it was fine...As soon as you started mixing $5 \mathrm{mls}$ and $5 \mathrm{mls}$ together using very simple laboratory mixing tubes and pipettes and what have you, we noticed that about $5 \%$ of the time it was a disaster...instead of having, making a milky solution which is what it should look like, we'd make something [that] looks more like a lava lamp, gunk and bits in it would occur. (Researcher 4)

In order to translate what had been small-scale laboratory work into something that could feasibly be given to patients, the scientists had to increase the quantities of lipid and DNA they were working with. But once they did so, portions of the mixed product became a biologically different, and difficult, thing-a thing, moreover, that the traditionally equipped laboratory could not accommodate. As this researcher recounts it, the consortium is portrayed as 
working a step ahead of the regulators, innovating solutions before the authorities had a chance to ask them to do so.

\begin{abstract}
And so the version that's often told is the regulators asked us how we were going to routinely mix these up. Actually we noticed already that it wasn't mixing well and so we had to think of a solution to do it. Of course, the solution came because someone said, "oh I mixed araldite using a syringe with 2 halves and a special mixture, shall we not try the araldite syringes and we did and they worked brilliant [...]" And then someone said "how fast are you going to press the syringe to make it mix?" So he built a machine that pressed it at a constant rate. ... you know we've already reached this place so we know we have to standardize things. It's exactly the example I was trying to give before. The regulators expect us to be experts, they expect us to predict the problems and present our solutions. We noticed a problem if we don't mix these things right, $5 \%$ of the time it is a catastrophe. [...]And I think one of the reasons that the field actually does move forward through those processes relatively easy is that there is an unwritten agreement between the scientists and the regulators, that the scientists have to tell it how it is. (Researcher 4)
\end{abstract}

Though the laboratory infrastructure is equipped with all the usual tools, in this case the biology of the gene therapy overwhelms them. The researchers' response is to elaborate upon what is already there, borrowing ideas and instruments where possible to produce the conditions needed to properly emulsify their therapeutic. The making of the syringes also enfolded scientists and regulators in a genial but somewhat opaque relationship. The former portray themselves as having devised a solution before the latter even knew there was a problem. Mediating between scientists, regulators, and a vulnerable patient population, the syringe becomes an agent of responsible science. The Consortium narrate their innovation of the syringe as partly necessity, meeting the practical need of making their drug in the correct form, but also in part as a positioning story through which they constitute themselves as the sort of scientific actors that regulators and patients expect them to be: capable, proactive, and innovative. The syringe comprises an essential piece of a broader gene therapy infrastructure, providing a material tool for making and moving the lipid-DNA composite, and also acting as a symbol of the researchers' creativity and competence. The modifications made to it also point to the adaptive flexibility of infrastructures, which can be extended or added to in order to navigate problems or obstacles. In this case, understanding the syringe as a piece of the trial infrastructure, and analyzing it as such, draws out the pragmatics and semiotics of the trial, both of which were important to the viability of the trial. Material resources and social positioning both play important roles in the creation and execution of this medico-scientific project.

"This story is told differently by other members of the team. 


\section{Defining and Recruiting the Patient Cohort}

Stabilizing the participant cohort was also central to laying the groundwork for the Phase II clinical trial. The trial design had to allow researchers to recruit a cohort from whom statistical evidence of the drug's safety and efficacy could be collected. During recruitment, patients were screened according to a number of inclusion and exclusion criteria. Alongside the ability to travel to the hospital monthly (to receive the drug and conform with dosing requirements), potential participants were evaluated according to their age and various health indicators.

A central inclusion criterion was lung health, measured via FEV (Forced Expiratory Volume in the first second), a standard tool in pulmonary medicine that measures the percentage of air a person can force out of their lungs in one second. The consortium members decided to

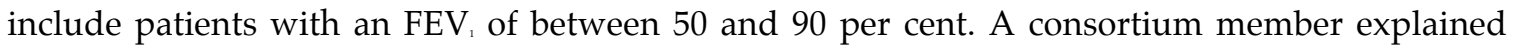
that with an $\mathrm{FEV}$, below 50\% (that is, a relatively weak expulsion of air) you don't know "if you're actually going to be able to deliver any of the gene therapy into their lungs," because the airways are presumably quite blocked up. Moreover patients with a low FEV, are less well than those with higher scores, and any side effects the drug might produce would be more detrimental because of that. "We don't want to make people who are sick, sicker," she added. In contrast, patients who had an $\mathrm{FEV}$, above $90 \%$ would potentially not benefit at all from the gene therapy, making their treatment somewhat pointless and the data produced unhelpful in the clinical trial context. "So it was always this balance between, can we deliver it, and then can we measure it. So we sort of cut our FEV figure in the middle" (Researcher 3). The consortium constructed their inclusion criteria such that they could assemble a group of participants to whom they could deliver the gene therapy with some success, and then measure its effects.

When it came to implementing the inclusion/exclusion criteria, the team members were careful to do so with some flexibility. The London group screened their database of 900 patients for age and lung function, but they made these parameters "slightly loose at the edges so that somebody who just happened not to be very well at the time might be better later and could get in, and similar[ly] at the top end" (Researcher 3). A team of clinical trial nurses went through the resulting long list and checked their records for other exclusionary factors. The prospective participants were then approached (in clinic, by phone, or by post) and the London site compiled a database of people's reasons for declining. Those "that were keen then obviously rolled in and got recruited" (Researcher 3). Along the way patients were screened for bacterial infections, and those with MRSA or atypical bacteria were excluded: “...we didn't want that muddying the water, but also the cross-infection issues means it's really difficult in the context of a trial" (Researcher 5). The need for clear efficacy data and the possibility of patients cross-infecting each other compound.

Despite having access to a larger patient population, it became clear that the London team were not going to enlist the requisite number of patients from their own site in a timely fashion. They decided to "make quite a big decision and go back to the ethics committee" for permission to recruit from Patient Identification Centers (PICs). "That was awful," explained Researcher 3, "there was this incredibly variable response rate [from the PICs], some of them very quick, some of them very slow, lots of hurdles to jump through, different at each center and 
really quite a frustrating process." The Phase II trial ultimately included some 140 participants recruited from 17 different sites in England and from throughout Scotland. Though modest by traditional clinical trial standards, this number allowed them to run the trial with a placebo control group, adding a control that is often absent from gene therapy trials.

The trial protocol, and especially the inclusion/exclusion criteria, facilitate the entrance of certain patient bodies into the clinical trial's remit, just as the developments of the split syringe facilitated the production of a properly mixed gene therapy, itself optimized to minimize side effects. Each of these elements adds to an infrastructure that brings geographically scattered and biologically varying patients into a productive arrangement with an experimental drug. Together they allow for the production of legible scientific evidence pertaining to the safety and efficacy of the gene therapy. This is the primary effect of infrastructures: they organize and connect, and in doing so to create new flows of information and objects that, ordered as such, in this case can produce a body of meaningful evidence. In the following sections, we analyze two further pieces of this infrastructure, which gave the consortium the means to directly produce and administer their CF gene therapy to enrolled patients. These artifacts demonstrate both the technical complexity of clinical gene therapy and the shifting dependencies and obligations the trial elicited.

\section{"Horse Trading" and "Donkey Work": The Pharmacy}

When the consortium began their collaboration, they had known that they would have to restructure their practice. They created a working group at each site, and went about setting up the necessary facilities for each of their respective foci. The group's efforts culminated in 2012, with the start of their Phase II clinical trial following the earlier work of safety testing and finding the patient cohort. This Phase II trial was to be run across both the London and Edinburgh sites, and whilst the former had most of the necessary facilities in place from earlier endeavors, the other had to put rather a lot of work into getting set up. "We had to tool up [our site] to be able to run the multi-dose study," explained one researcher, "because we always knew that would have to be at two sites in order to get enough patients in. That was quite a difficult process, actually. There was a lot [that] needed to be done to the pharmacies there and to the systems that they had in place" (Researcher 3).

Classed as Advanced Therapy Medicinal Products (ATMPs) by the EU, gene therapy "products" (the vector-DNA compound) intended for human application have to be made to strict manufacturing standards called "Good Manufacturing Practice," or GMP. The result is a complex assortment of validated constituent parts (reagents, antibodies) of known origin ("traceability"), held together by an array of practices that must be learnt, taught, and rigorously recorded, Furthermore, all activities must be carried out in certified facilities by trained personnel. For the consortium, the manufacturing process was further complicated by the temporal requirements of their particular gene therapy, which could only be defrosted and mixed a few hours before a patient was due to be treated. They thus needed an infrastructure that 
brought GMP requirements and the gene therapy production process together, and that also made the treatment process itself as efficient as possible.

The Brompton hospital in London was not GMP certified when the consortium began their pilot testing, but they learnt that a nearby hospital had the necessary licenses and established a collaboration of sorts with them. When it came to expanding to Edinburgh for the Phase II work, finding pharmacy facilities proved more complicated. Researcher 5 narrated this process during an interview:

One of the stumbling blocks was the fact that [Edinburgh's] pharmacy did not have the capacity to house our study. Mostly that was because they physically didn't have the space and they didn't have a cabinet that was an isolator that would be sole use for us and as you can imagine with the risk assessment that we were going through...the expectation was that we would probably require this. We didn't quite know because we hadn't got to the end of it, however we were all thinking, "what we don't want is our stuff to contaminate anyone else or anyone else to contaminate our stuff," so we really needed our own cabinets ourselves. So, there was not the space, nor the cabinet, or the space to put the cabinet.

It was not only the GMP specifications that made finding pharmacy facilities difficult in Edinburgh. The researchers also did not know for sure whether contamination was likely to be an issue for them and those around them; nor were they sure what the regulators take on this would be. This double uncertainty inclined the consortium to build cautiously around their own ideas of contamination and safety. They did so by seeking out dedicated physical facilities for their production process, materializing another arm of an infrastructure that could support a scientifically complex and uncertain trial.

Facing a dearth of useful facilities in Edinburgh, the team began exploring other options, including setting up in a manufacturing site that was being built at the time. Though the timing for that did not work out, they did acquire some money to build a pharmacy of their own shortly thereafter thanks to a benevolent contact in a funding agency. Finances in hand, the consortium approached the regional National Health Services (NHS) Estates Department, which allocates space. They were told that one room in Edinburgh would fit their purpose, located in the Outpatients Department of a nearby hospital. Researcher 5 explained:

We have an Edinburgh University footprint which means that basically we have some areas in there that NHS Lothian allow us to use in kind for other things they get from Edinburgh University, so we had...quite a large footprint in that area, however the one room that we required belonged to somebody else, so we did some horse trading and my staff spent numerous hours doing lots of things in kind for the other department and by that I just mean moving things, filing things, doing lots of donkey work for them to actually just swap over two rooms.

Putting together an infrastructure that could support the activities of the CF clinical trial involved acquiring access to NHS's pre-existing built infrastructure, which was essentially traded 
for various forms of labor on the part of Consortium staff. The researchers' attempts to set up the space for their work continued in an absence of regulatory guidance or specificity. They based much of the pharmacy's development on London's facilities. However, as one team members recalled, "it was all guesswork, it was all let's take this, let's read the guidelines, let's ask as many pharmacists...as many people as possible, and try and pull together as good a thing as we can for the money we have, on the limited knowledge we have." She continued, "at some points you honestly thought it was never going to work because you were really basing it on, you know, as much internet trawling as you could do." Again, the patchwork of knowns and unknowns-empiric and regulatory-provide uneven grounds for the researchers to build their project upon.

Financing the pharmacy was also a challenge, especially after cuts from the original funders left the group figuring out where they could save money and where investment was nonnegotiable. Researcher 5 recalls speaking with their funder, who, "at the start had said 'well if we future proof this how much would it cost?' and that's when I say [I] stopped counting [at] $£ 100,000$, got back to him and he says 'umm...,' he is like, 'no you're right, we are not going for that.'" The pharmacy room itself ended up costing the consortium approximately $£ 45,000$ ("and that was almost flipping in there painting it myself"), plus a further $£ 20,000$ for isolators, and $£ 70,000$ for converting the cubicles that patients would sit in for treatment. Though they hired a pharmacist especially for the job, the consortium was fortunate that that same funder allowed them to "borrow" a laboratory technician as needed.

Equipping the pharmacies in London and Edinburgh saw the consortium navigating tight and unpredictable funding, seeking out advice and support from their contacts, and trying to pre-empt what various regulatory agencies might expect of them. The pharmacy was essential to producing a gene therapy to GMP standards, and doing so in a way that would protect others from hypothetical contamination; it enabled the researchers to bring in certified materials and turn them into an ATMP that can then be defrosted on-site and delivered to patients, and inhaled into their afflicted lungs. In other words, as a key node in the gene therapy trial infrastructure, the pharmacy operated as a space that allowed for the entry, modification, and transmission of biological substances. However, it also, crucially, provided a space in which this circulation of experts and therapy could be brought into line with established and emergent standards. And yet this crucial arm of the trial infrastructure rests as much on imagined expectations as it does on NHS territory, propped up by generous benefactors and the "donkey work" of the team.

\section{"We Had to Knock Down Walls": The Cubicles}

If certified facilities are central to ensuring that a gene therapy is appropriately produced, further assurance is necessary that any possible risks of both the product and its production are adequately minimized. A (favorable) local risk assessment was required, but, again, uncertainties as to how to achieve this abounded. The Edinburgh group adapted London's risk assessment to

- This is one aspect of infrastructures that we do not have the space to discuss here: the ways in which multiple infrastructures intersect and overlay to create an increasingly complex traffic of goods, ideas, and meanings, and with them, of course, extended dependencies, obligations, supports and so on. 
both the new site and new (multi-dose) protocol. Reflecting on this, Researcher 5 recalled that "nobody was quite sure what the right questions were to ask, however you just had to take a stab at what you think would be a question that should be answered. So for instance, exposure."

The research team had long since concluded that the best delivery method for their gene therapy was inhalation. In many ways the lungs seemed custom made for such treatment: a natural passage that facilitated the continual intake (and exhalation) of molecules, therapeutic or otherwise. Exhalation, however, meant the therapy would be almost immediately expelled, and this in turn raised the possibility of others inhaling it. The consortium needed to develop a way of containing the therapy during its administration. In earlier London studies it had transpired that a nearby allergy department possessed custom-made cubicles in which patients could be exposed to particular allergens (flour, paint) in a contained environment: negative pressure ventilation allowed air to flow in, but not back out. The researchers borrowed these booths for the pilot trial, and found them to be effective. However, when it came to the Phase II trial more booths were needed to accommodate the higher patient numbers, and some of those had to be in Edinburgh. The consortium acquired funding to bring in more, but at the new site they "had to knock down walls and wait...to have one delivered and then the wrong size one came and we had to knock another wall down and this sort of thing."

The breathing booths epitomize the material improvisation that the consortium employed to produce the conditions in which their trial could proceed. Researcher 5 gave the question of exposure as one example of how "risk" was pre-empted by the research group. (And as colleagues made clear, it was very much pre-emptive: "It's identified by the scientists, there wasn't anything that anyone ever forced upon us.") Risks related to exposure are two-fold. In the first case, Cystic Fibrosis patients are advised not to interact with each other to avoid crossinfecting each other with the infections CF makes them susceptible to." Additionally, there is the issue of containing the therapeutic itself. Researcher 4 explained: "We have gene therapy which is this slightly alarming thing and we are asking people to breathe it in. They are also going to breathe it out and so the point of the booths is to contain the material they breathe out to some degree and to isolate it from the rest of the world so it doesn't spread everywhere." He went on to question the necessity of this.

You could ask how much of a problem would that have been. Probably not much of a problem actually, but the sort of philosophy of the hospital was let's build this structure so that it would work for any form of gene therapy even if it was a viral type...It was probably more than is needed for non-viral but it's also suitable for future trials. So, it was sort of built looking forward to the future really.

The breathing booths are a physical manifestation of the ad hoc methods by which the consortium could set up a space for their work. This object drew together regulatory concerns about risk and containment, the opportunistic adoption of tools (the cubicles) and knowledge

: In fact, the presentation of the trial's results, with which we opened this paper, had been preceded by a notice asking patients not to come, but rather to follow along online for this same reason. 
(smoke exhalation studies), and the workings of the gene therapy itself. Considering the booths as parts of the larger gene therapy infrastructure demonstrates how precaution and precision came to be built into the trial through its physical make-up, and the corresponding alignment of patients, researchers, and regulators.

\section{Discussion}

There has been renewed interest and writing on infrastructures in STS and cognate disciplines. Our analysis speaks to the analytic purchase of an infrastructural focus: here it has allowed us to show how risk and uncertainty coalesced with regulatory concerns and the practicalities of, for example, mixing the DNA and vector. While they are produced with and channel sociopolitical norms, infrastructures are in our definition primarily material, and a commitment to analyzing their material makeup and effects opens up the pragmatics of scientific work for examination. Three key points might be taken away from our analysis. Infrastructures (1) enable and curtail the movement of matter, which (2) allows for uncertainty to be accommodated, even contained, in experimental settings, and thus (3) bridge the separations that are seen as essential for ensuring, e.g., the health of CF patients, or the safety of gene therapy. Moreover, these points speak to the double task of infrastructures: that they selectively enable the movement of people and things.

We could have framed this collaborative scientific endeavor in relation to Actor Network Theory (ANT), or interpreted it in the language of assemblages, choreography, or articulation. We have chosen instead to think about the trial infrastructure, and in doing so foreground the distributive, material activity that this experimental science relies on. An infrastructural focus lends itself to analysis of how purposeful connections are made in a context of epistemic and regulatory uncertainty. There is a politics to infrastructures' distributive action, which is itself twofold, because whilst infrastructures enable and delimit the movement of matter, they also mediate the very activity that they provide the grounds for. The gene therapy researchers were working in a context of multiple uncertainties regarding not only how to do gene therapy, but also how to anticipate and enact ambiguous regulatory requirements in a context of limited resources (technical, spatial, and financial). At the same time, the trial infrastructure had to accommodate Cystic Fibrosis biology by bridging the gap between pathology and therapy. The consortium's approach to treating CF required that they address concerns about contamination and safety while finding a way of getting a modified gene product into the lungs of the trial participants.

Analyzing the case we have presented here through the notion of infrastructures allowed us to identify the many uncertainties that inhere in experimental science as constitutive elements of this work--elements that require tangible workarounds to be either overcome or made into resources by virtue of their own lack. We see this in how the researchers are able to recast the unknowns of gene therapy's safety into hallmarks of their own responsible and proactive practice. Take the researchers' explanation regarding the containing properties of the breathing booths, for example, which they viewed as quite likely excessive in relation to the actual gene 
therapy and its possible risks. Thinking about the booths in infrastructural terms, in relation to the rest of the trial's material make-up, points to the double task of this particular infrastructure. While the trial infrastructure is set up to allow for a traffic of gene therapy materials, practices, and concepts across the three trial sites, this distributive action is selective. If we return to Larkin's "matter that enables the movement of other matter," we see that some of the matter being moved is also being contained and confined. Building the trial infrastructure around uncertainties to do with risk and contamination means making it as protective as it is distributive. As "objects that create the grounds on which other objects operate," the infrastructure is not only supportive of scientific production, but also provides the grounds for enacting responsible research practice and proactive governance.

Previous research from Science and Technology Studies has examined the governance of laboratory space by regulators. ${ }^{.}$While this scholarship demonstrates the effects of state regulation on scientific practice, it stops short of providing a frame for assessing their broader socio-political significance. In bringing various people, tools, and small entities into a particular relationship, the trial infrastructure endowed them with political and medical importance. It produced the connections needed for the production of findings, a physical space for the practice of gene therapy, and an environment where an active patient collective could contribute to its (perhaps healthier) future. We thus agree with Larkin that infrastructures are things as well as the relations between them. These relations are productive: they transform patients into human subjects, breathing booths into artifacts of state-science relations, and research teams into purveyors of good scientific practice.

The trial infrastructure enabled and delimited the movement of the CF gene therapy, from its production in the pharmacy to the pulmonary organs of the study participants. In contrast to concepts that point to relationality and entanglements in scientific practice, the language of infrastructure draws out the irreducible material needs and limits of a given situation, and thus allows us to give shared attention to relations between the politics and the pragmatics of (in this case) getting experimental science done.

\section{Conclusion}

This project has been our entry point for making sense of how infrastructures are made and what role they play in furthering experimental biomedicine. What the consortium members call "tooling up" we read as the early stage production of an infrastructure that could support a gene therapy clinical trial for Cystic Fibrosis. Talk of walls being knocked down and rooms borrowed is infrastructural in the most colloquial sense. Adhering to our earlier definition, however, this infrastructure included breathing booths, custom-made syringes, pharmacy spaces,

\footnotetext{
- Writing on the tension between laboratory workers and safety personnel, for example, Mody (2001) demonstrates how tensions over cleanliness emerge through competing ideas of moral order. In his study of high-energy physics, Galison (1997) describes how in the wake of a fire at major research facility, US regulators were able to impose their view of laboratory research, resulting in more formalized work environment that altered the organization and future of experimental physics.
} 
inclusion/exclusion criteria, and a carefully chosen lipid-DNA construct, amongst other things. Together these facilitated the scientific activity of the consortium, the essential traffic of (certain) patients' bodies into experimental medical spaces, of DNA into those patients' bodies, and, later, of data on the interaction of those bodies and therapies, as we saw in Alton's presentation of the trial's results.

Because the consortium began their work at a time when clinical gene therapy was relatively new and non-viral gene therapy especially uncommon, they had to construct an infrastructure that could both supply their scientific needs and span the many knowledge gaps and uncertainties around the risks and regulation of their work. The Consortium needed to conduct their clinical trial, which is to say, they needed to produce a body of clinically derived evidence on the safety and efficacy of their gene therapy. Moreover, they needed to do so in a context where regulatory agencies are charged to "protect and promote the interests of patients and the public in health and social care research," but where those same agencies lack information or experience specific to this science. The resulting infrastructure thus networked together conceptual instruments (like the inclusion/exclusion criteria) and material objects (breathing booths, split syringes) according to a guesswork based on comparisons (e.g. with smoke exhalation research), "internet research," and cautionary estimates about risk and contamination. The resulting infrastructure embodied the normative commitments of the researchers, informed as it was by a broader regulatory ethos.

\section{Author Biography}

Samuel Taylor-Alexander is Research Fellow in Anthropology at Monash University. He has held academic posts at the University of Auckland and the University of Edinburgh as well as visiting positions at Harvard University (STS) and the University of Copenhagen (Anthropology). His work is published in Medical Anthropology Quarterly, Current Anthropology, New Genetics and Society, Molecular Therapy and Science. Samuel is the author of On Face Transplantation: Life and Ethics in Experimental Biomedicine (Palgrave Macmillan).

\section{Author Biography}

Courtney Addison is an anthropologist of science and medicine, and Research Assistant at Monash University. Her doctoral research examined the politics of ethics and knowledgeproduction in the context of gene therapy through London-based hospital ethnography. Her work is published in Biosocieties, New Genetics and Society and Medical Anthropology.

\section{Acknowledgements}

We would like to thank the members of the UKCFC for their time, participation, and support for this article. Thanks also to the Science and Governance Reading Group at the University of Edinburgh for providing valuable feedback on an early draft of this paper; thanks in particular to 
Martyn Pickersgill, Sarah Chan and Edward Dove for their detailed comments. A previous version of this article was presented at the Science and Democracy Network 2016 meeting. Our thanks as well to Daniel Lee Kleinman and Katie Vann for their editorial guidance, and to the anonymous reviewers. STA's research was funded by Wellcome Trust Senior Investigator Award No: WT103360MA (PI: Graeme Laurie), "Confronting the Liminal Spaces of Health Research Regulation." As part of the University of Copenhagen's Consortium for Designer Organisms, CA's research was funded by the UCPH Excellence Fund for Interdisciplinary Research.

\section{References}

Alton, E. M. Stern, R. Farley, A. Jaffe, S.L. Chadwick, J. Phillips, J. Davies, S.N. Smith, J Browning, M.G. Davies, M.E. Hodson, S.R. Durham, D. Li, P.K. Jeffery, M. Scallan, R. Balfour, S.J. Eastman, S.H. Cheng, A.E. Smith, D. Meeker and D.M. Geddes. 1999. "Cationic lipidmediated CFTR gene transfer to the lungs and nose of patients with cystic fibrosis: a double-blind placebo-controlled trial." The Lancet 353(9157): 947-954.

Christen, K. 2006. "Tracking properness: repackaging culture in a remote Australian town." Cultural Anthropology, 21(3): 416-446.

Collier, S. J. 2011. Post-Soviet social: neoliberalism, social modernity, biopolitics. Princeton: Princeton University Press.

Corvol, H. K. E. Thompson, O. Tabaray, P. le Rouzic and L. Guillot. 2016. "Translating the genetics of cystic fibrosis to personalized medicine." Translational Research 168: 40-49.

Foucault, M. 2012. The birth of the clinic. Oxfordshire: Routledge.

Galison, P. 1997. Image and logic: A material culture of microphysics. Chicago, London: University of Chicago Press.

Gardner, J. and A. Webster. 2016. "The social management of biomedical novelty: Facilitating translation in regenerative medicine." Social Science and Medicine 156: 90-97.

Geissler, P. 2013. "Public secrets in public health: Knowing not to know while making scientific knowledge." American Ethnologist 40(1): 13-34.

Gibbons, M., C. Limoges, H. Nowotny, S. Schwartzman, P. Scott and M. Trow. 1994. The new production of knowledge: The dynamics of science and research in contemporary societies. London: Sage.

Harvey, P. and H. Knox. 2012. “The enchantments of infrastructure.” Mobilities, 7(4): 521-536.

Howe, C. J. Lockrem, H. Appel, E. Hackett, D. Boyer, R. Hall, M. Schneider-Mayerson, A. Pope, A. Gupta, E. Rodwell, A. Ballestero, T. Durbin, F. el-Dahdah, E. Long and C. Mody. 2016. "Paradoxical Infrastructures: Ruins, Retrofit, and Risk." Science, Technology \& Human Values 41(3): 547-565.

Keating, P. and A. Cambrosio. 2003. Biomedical platforms: realigning the normal and the pathological in late-twentieth-century medicine. MIT Press.

Jasanoff, S. 2013. “Epistemic Subsidiarity - Coexistence, Cosmopolitanism, Constitutionalism." European Journal of Risk Regulation 4(2): 133-141. 
Jensen, C.B. and A. Morita. 2015. "Infrastructures as Ontological Experiments." ESTS Journal 1: 81-87.

Larkin, B. 2013. "The politics and poetics of infrastructure." Annual Review of Anthropology, 42: 327-343.

Marcus, G. E. and E. Saka. 2006. “Assemblage." Theory, Culture and Society 23(2-3): 101-109.

Mody, C. 2001. "A little dirt never hurt anyone: Knowledge-making and contamination in materials science." Social Studies of Science 31(1): 7-36.

Petryna, A. 2005. "Ethical variability: drug development and globalizing clinical trials." American Ethnologist 32(2): 183-197.

Simone, A. 2004. "People as infrastructure: intersecting fragments in Johannesburg." Public Culture 16(3): 407-429.

Star, S. L. 1999. "The ethnography of infrastructure." American Behavioural Scientist 43(3): 377-391.

Street, A. 2014. Biomedicine in an unstable place: Infrastructure and personhood in a Papua New Guinean hospital. Durham, NC: Duke University Press.

Street, A. 2016. "The hospital and the hospital: Infrastructure, human tissue, labour and the scientific production of relational value." Social Studies of Science 46(6): 938-960.

Timmermans, S. and M. Berg. 2010. The gold standard: The challenge of evidence-based medicine and standardization in health care. Philadelphia: Temple University Press.

Vertesi, J. 2014. "Seamful spaces: Heterogeneous infrastructures in interaction." Science, Technology \& Human Values 39(2): 269-284. 